\title{
SIMPLE URINE METABOLIC SCRENING IN CHILDREN WITH REFRACTORY EPILEPSY IN ZAGAZIG UNIVERSITY CHILDREN'S
}

\author{
${ }^{1}$ Fatma Elzhraa Tawfik, ${ }^{1}$ Mohamed Naguib Abo-Alfotoh, ${ }^{1}$ Mohamad Ahmad Arafa, ${ }^{2}$ Naglaa Ali \\ Khalifa
}

Department of pediatrics ${ }^{1}$, clinical pathology ${ }^{2}$, faculty of medicine, zagazig university, Egypt.

Received: 3 October 2018

Accepted: 25 December 2018

Corresponding Author

eng_ahmedrashaad@yahoo.com

$+201010459556$

\section{ABSTRACT}

Background: Epilepsy is one of the most common serious neurological conditions and $20 \%$ to $30 \%$ of people with epilepsy have repeated seizures attacks that develop refractory epilepsy .The aim of the present study was to examine the inherited metabolic abnormalities in children with refractory epilepsy to provide early etiological and symptomatic treatment. Patients are to have refractory epilepsy if the application of two types of appropriate and tolerable antiepileptic drugs failed to completely prevent epileptic seizure following adequate duration of treatment and adequate doses of drugs Refractory epilepsy always has been a problematic issue in neurology particularly in the infantile period when the brain of children develops rapidly. An increasing number of children with refractory epilepsy are mainly focused on hereditary metabolic disorder .Since most inherited metabolic disorder are lacking in specific symptom, they are easily ignored or missed in clinical diagnosis.

Methods: This study was applied to forty eight patients with refractory epilepsy by application of urine metabolic screen by using urine test strips ,Benedict test, ferric chloride test, Nitrosonaphthol test,Cyanidenitroprusside test,2. 4 dinitrophenyl hydrazine test.

Result: In our study regarding urine screening tests $42 \%$ of our cases had presented positive results in at least one of the urine screening tests. This denotes the importance of urine screening tests for early detection of metabolic diseases among cases of refractory epilepsy.

Conclusion :Compared with the positive rate of the urine metabolic screening tests in high risk infants

suggest probability of the presence of a metabolic disease, which will need further investigations

Key Words : refractory epilepsy, metabolism, Screening

\section{INTRODUCTION}

E pilepsy is a common children's neural disease (1). Refractory epilepsy May be defined as failure of complete or acceptable control of seizures in response to the antiepileptic drugs. For routine use, failure of seizure-control despite trial of three appropriate anti-epileptic drugs (AED) regimens at maximum tolerated doses should be considered as drug- refractoriness and is highly likely to indicate failure with subsequent AED trials. Another important concern is 'pseudo' or 'apparent' refractoriness. It should be excluded before a diagnosis of refractory epilepsy (2). The factors to be considered includes appropriateness of the drug for the epilepsy syndrome, compliance, 'seizure mimickers', adequate dosing and trial and drug interactions .The pathogenesis of refractory epilepsy is complicated, and remains to be clarified. The development of molecular genetics and biochemistry have led to the finding that refractory epilepsy is closely associated with inherited metabolism(3)(4). An increasing number of children with refractory epilepsy are mainly focused on hereditary metabolic www.zumj.journals.ekb.eg 
disorder (5).Inherited metabolic disorders are a manifestation, including organic acids, amino acids, fatty acids metabolic disease, which are incurred by disorder of biochemical metabolism and the accumulation of toxic products and the accumulation or insufficiency of metabolites resulting from the structural defects or functional disorders of protein arising from gene mutation (6)(7). The symptoms depend on the particular metabolic pathway that is affected (8).Clinical features of metabolic disorders are non-specific and none of these features alone may point towards a metabolic disorder, so the recent advances in the diagnosis and treatment of inherited metabolic disorders have improved the diagnoses for many of these conditions (9). Method :This study includes 48 patients with refractory epilepsy, cross section study . Urine metabolic screening for all subjects: $25 \mathrm{ml}$ of series of metabolic defects of different clinical random sample of urine was collected from each patient in a sterile plastic container containing $0.5 \mathrm{ml}$ of $6 \mathrm{~N} \mathrm{HCl}$ as preservative. Urine sample was screened for any physical variations in colour, appearance, $\mathrm{pH}$, specific gravity. using urine test strips ,Benedict test,ferric chloride test, Nitrosonaphthol test,Cyanide-nitroprusside test,2,4 dinitrophenyl hydrazine test

Results :urine screening tests $42 \%$ of our cases had presented positive results Benedict test was positive in $17 \%$ of cases, 2,4 dinitrophenyl hydrazine test was positive in $4 \%$ of our patients ,Nitrosonaphthol test was positive in $6 \%$ of our patients, Ferric chloride test was positive in $13 \%$ of our patients cyanide nitroprusside test was positive in $2 \%$ of our patients.

Table 1 Family and developmental history of the studied children

\begin{tabular}{|l|l|l|l|}
\hline \multicolumn{2}{|c|}{ Variables } & $\boldsymbol{n}$ & \% \\
\hline \multirow{2}{*}{ Consanguinity } & Negative & 22 & 46 \\
\cline { 2 - 4 } & Positive & 26 & 54 \\
\hline \multirow{2}{*}{$\begin{array}{l}\text { Unexplained illness or } \\
\text { death }\end{array}$} & Negative & 28 & 58 \\
\cline { 2 - 4 } Developmental delay & Positive & 20 & 42 \\
\cline { 2 - 4 } & Negative & 13 & 27 \\
\cline { 2 - 4 } & Positive & 35 & 73 \\
\hline
\end{tabular}

Total number $=48$

Table 2 Clinical characteristics of the studied children

\begin{tabular}{|l|l|c|c|}
\hline \multicolumn{2}{|c|}{ Variables } & $\boldsymbol{n}$ & \% \\
\hline \multirow{2}{*}{ Dysmorphic facies } & Negative & 17 & 35 \\
\cline { 2 - 4 } & Positive & 31 & 65 \\
\hline \multirow{2}{*}{ Jaundice } & Negative & 39 & 81 \\
\cline { 2 - 4 } & Positive & 9 & 19 \\
\hline \multirow{2}{*}{ Seizure type } & General & 28 & 58 \\
\cline { 2 - 4 } & Partial & 13 & 27 \\
\cline { 2 - 4 } & General+ Partial & 7 & 15 \\
\hline \multirow{2}{*}{ Organomegaly } & Negative & 29 & 60 \\
\cline { 2 - 4 } & Positive & 19 & 40 \\
\hline \multirow{2}{*}{ Vomiting } & Negative & 35 & 73 \\
\cline { 2 - 4 } & Positive & 13 & 27 \\
\hline \multirow{2}{*}{$\begin{array}{l}\text { Episode of coma or } \\
\text { encephalopathy }\end{array}$} & Negative & 22 & 46 \\
\cline { 2 - 4 } & Positive & 26 & 54 \\
\cline { 2 - 4 } & Negative & 23 & 48 \\
\cline { 2 - 4 } & Positive & 25 & 52 \\
\hline
\end{tabular}


Table 3 Data of urine screening tests

\begin{tabular}{|c|c|c|c|}
\hline \multicolumn{2}{|l|}{ Variables } & $n$ & $\%$ \\
\hline \multirow[t]{2}{*}{ Benedict test } & Negative & 40 & 83 \\
\hline & Positive & 8 & 17 \\
\hline \multirow[t]{2}{*}{ DNPH } & Negative & 46 & 96 \\
\hline & Positive & 2 & 4 \\
\hline \multirow[t]{2}{*}{ Nitrosonaphthol } & Negative & 45 & 94 \\
\hline & Positive & 3 & 6 \\
\hline \multirow[t]{2}{*}{ Cyanide nitroprusside } & Negative & 47 & 98 \\
\hline & Positive & 1 & 2 \\
\hline \multirow[t]{2}{*}{ Ferric chloride } & Negative & 42 & 87 \\
\hline & Positive & 6 & 13 \\
\hline \multirow[t]{2}{*}{ Toluidine blue } & Negative & 48 & 100 \\
\hline & Positive & 0 & 0 \\
\hline
\end{tabular}

Table 4 Patients' Family and developmental history \& positive urine screen tests

\begin{tabular}{|c|c|c|c|c|c|}
\hline $\begin{array}{c}\text { Family and } \\
\text { developmental history }\end{array}$ & Benedict test & DNPH & Nitrosonaphthol & $\begin{array}{c}\text { Cyanide } \\
\text { nitroprusside }\end{array}$ & $\begin{array}{l}\text { Ferric } \\
\text { chloride }\end{array}$ \\
\hline \multicolumn{6}{|l|}{ Consanguinity } \\
\hline$n$ & $5 / 26$ & $0 / 26$ & $2 / 26$ & $1 / 26$ & $3 / 26$ \\
\hline$\%$ & $19 \%$ & $0 \%$ & $8 \%$ & $4 \%$ & $11.5 \%$ \\
\hline \multicolumn{6}{|c|}{ Unexplained illness or death } \\
\hline$n$ & $3 / 20$ & $2 / 20$ & $1 / 20$ & $1 / 20$ & $5 / 20$ \\
\hline$\%$ & $15 \%$ & $10 \%$ & $5 \%$ & $5 \%$ & $25 \%$ \\
\hline \multicolumn{6}{|l|}{ Developmental delay } \\
\hline$n$ & $5 / 35$ & $2 / 35$ & $3 / 35$ & $1 / 35$ & $4 / 35$ \\
\hline$\%$ & $14 \%$ & $6 \%$ & $9 \%$ & $3 \%$ & $11 \%$ \\
\hline
\end{tabular}

Table 5 Patients' clinical characteristics and positive urine screening tests

\begin{tabular}{|c|c|c|c|c|c|}
\hline Clinical characteristics & Benedict test & DNPH & Nitrosonaphthol & $\begin{array}{c}\text { Cyanide } \\
\text { nitroprusside }\end{array}$ & $\begin{array}{c}\text { Ferric } \\
\text { chloride }\end{array}$ \\
\hline \multicolumn{7}{|c|}{ Dysmorphic facies } \\
\hline $\boldsymbol{N}$ & $4 / 31$ & $2 / 31$ & $3 / 31$ & $1 / 31$ & $5 / 31$ \\
\hline Jaundice, $\boldsymbol{n}$ & $13 \%$ & $7 \%$ & $10 \%$ & $3 \%$ & $16 \%$ \\
\hline \multicolumn{7}{|c|}{ Seizure type } \\
\hline \multicolumn{7}{|c|}{ General, } \\
\hline $\boldsymbol{N}$ & $2 / 9$ & $2 / 28$ & 0 & 0 & $1 / 9$ \\
\hline \% & $6 / 28$ & $7 \%$ & $7 \%$ & $0 / 28$ & $4 / 28$ \\
\hline Partial, $\boldsymbol{n}$ & $21 \%$ & $0 / 13$ & $0 / 13$ & $0 / 13$ & $0 / 13$ \\
\hline General+ Partial, $\boldsymbol{n}$ & $0 / 7$ & $0 / 7$ & $1 / 7$ & $1 / 7$ & $2 / 7$ \\
\hline Hypotonia, $\boldsymbol{n}$ & $0 / 19$ & $2 / 19$ & $1 / 19$ & $0 / 19$ & $3 / 19$ \\
\hline Organomegly, $\boldsymbol{n}$ & $5 / 13$ & $0 / 13$ & $2 / 13$ & $0 / 13$ & $2 / 13$ \\
\hline
\end{tabular}




\section{DISCUSSION}

Inborn errors of metabolism (IEM) are the consequence of genetic defects that lead to a metabolic block in a biochemical pathway critical to cellular function, targeting many organs including the brain. The resultant biochemical disturbance results in neuronal dysfunction and the development of epileptogenesis through complex cellular mechanisms that may be specific to each disorder. Epilepsies associated with IEM share certain features. An early age of presentation, co-morbid developmental delay/regression, and resistance to conventional antiepileptic drugs (10). The cross sectional study was carried out at the pediatrics department and clinical pathology department ,zagazig university hospitals to study Inborn errors of metabolism in infant $s$ and children with refractory epilepsy for early intervention and proper treatment to be provided ,thereby effectively controlling patient seizures and improving their distant prognosis In our study developmental delay was the predominant symptom (73\%), dysmorphic

facies(65), consanguinity(54), vomiting (54\%). episodes of encephalopathy(52), hypotonia(40\%)"'"(11) and This in agreement with a study conducted in Neurology Department, Cairo University Children Hospital by Laila et al., 2009(12) on Eight hundred patients attending the neurometabolic clinic at Cairo University Children Hospital (CUCH) screened for inborn errors of metabolism (IEM) by MS/MS. Developmental delay was a dominant symptom being present in $(84.2 \%)$, vomiting in $(63.2 \%)$, encephalopathy with episodes of encephalopathy $(57.8 \%)$, seizures in $(42 \%)$. IEM may be accompanied by developmental delay or regression, seizures, nystagmus, abnormal muscular tonus, or abnormal movements. Recurrent episodes of lethargy, ataxia, seizures, or strokes can reveal an underlying metabolic disorder such as ornithine transcarbamylase deficiency, organic acid disorders, maple syrup urine disease, homocystinuria, and mitochondrial
disease.Patients with creatine synthesis defects may present with growth failure and seizures (13) Vomiting is commonly episodic in metabolic disorders and leads frequently to FTT. worsening of vomiting during intercurrent illnesses, or a finding of lethargy or acidosis are highly suggestive of an underlying metabolic disease such as urea cycle defects, organic acid disorders, amino acid disorders, hereditary fructosemia, galactosemia, fatty acid oxidation defects, or mitochondrial disorders (14). Regarding consanguinity in our case group, it was present in $54 \%$ of all cases. Of these cases $19 \%$ had positive Benedict test, $8 \%$ had positive Nitrosonaphthol test, $4 \%$ had positive cyanide nitroprusside test and $11.5 \%$ had positive ferric chloride test. These results are in agreement with Mokhtar et al., 1998(15) who found a significant incidence of consanguinity among metabolic diseases.

In this study 20 out of 48patients (42\%) who were included in the study had siblings with unexplained illness or death. Of these cases $15 \%$ had positive Benedict test, $10 \%$ had positive DNPH test, $5 \%$ had positive Nitrosonaphthol test, $5 \%$ had positive Cyanide nitroprusside and $25 \%$ had positive ferric chloride test.

These results are in agreement with Greenberg,2002(16).. In this study 9 out of 48 patients (19\%) who were included in the study presented with jaundice in association with refractory epilepsy of theses cases 2 of cases had positive Benedict's test and 1of cases had positive ferric chloride.

Inborn errors may present with any of the characteristic features of liver disease. Conjugated or unconjugated hyperbilirubinemia can be caused by IEM. Patients with classical galactosemia usually present with vomiting, lethargy, hyperbilirubinemia, and liver failure in the first weeks of life. Reye-like acute encephalopathy with hepatocellular dysfunction is highly suggestive of fatty acid oxidation defects. Conjugated hyperbilirubinemia associated with some dysmorphic features and hearing loss can be caused by a defect in peroxisomal biogenesis. Neonatal cholestasis 
can also be caused by bile acid synthesis or transport defects, congenital glycosylation defects, tyrosinemia type 1 , or lysosomal storage disorders such as Niemann-Pick disease type C. The coagulopathy associated with metabolic liver disease is often severe but may not be clinically apparent. Therefore, screenings for liver dysfunction, when there is suspicion of an underlying metabolic disorder, should always include prothrombin time, partial thromboplastin time, and fibrinogen.The presence of hepatosplenomegaly with slowly progressive psychomotor retardation suggests a diagnosis of a lysosomal storage disease (17).

In this study 31 out of 48 patients (65\%) who were included in the study presented with dysmorphic facies in association with refractory epilepsy. Of these cases $13 \%$ had positive Benedict test, $7 \%$ had positive DNPH test, $10 \%$ had positive Nitrosonaphthol test, $3 \%$ had positive cyanide nitroprusside test , $16 \%$ had positive ferric chloride test..

Structural cerebral abnormalities and/or mild dysmorphic features can indicate energy metabolism defects such as mitochondrial disorders

In this study 19 out of 48 patients (40\%) who were included in the study presented with hypotonia in association with Refractory epilepsy of theses cases 2 had positive DNPH test, 1 had positive Nitrosonaphthol test, 0 had positive cyanide nitroprusside test, 0 had positive toluidine blue test and 3 had positive ferric chloride test. In this study 13 out of 48 patients $(27 \%)$ who were included in the study presented with organomegaly in association with Refractory epilepsy of theses cases 5 had positive Benedict's test, 0\% had positive DNPH test, 2 had positive Nitrosonaphthol test, 0 had positive cyanide nitroprusside test, $0 \%$ had positive toluidine blue test and 2 had positive ferric chloride test.

In this study 25 out of 48 patients (52\%) who were included in the study presented with episodes of coma in association with Refractory epilepsy of these cases $20 \%$ had positive Benedict's test, $8 \%$ had positive DNPH test, $12 \%$ had positive Nitrosonaphthol test, $0 \%$ had positive cyanide nitroprusside test, $0 \%$ had positive toluidine blue test and $24 \%$ had positive ferric chloride test.

Coma, organomegaly, seizures, developmental delay are significantly present in association with inborn errors of metabolism in many centre studies

.Although each individual disease is rare but the whole sum of these metabolic disorders are not rare. The rarity of these disorders, different modes of presentation, atypical forms should raise the necessity for screening for these disorders to early pick up these cases to offer family counselling, early treatment and possibly early detection of these disorders in their siblings.. In this study showed no significant association between clinical data and urine metabolic screening test in the studied children due to study limitation. STUDY LIMITATION: 1- Relatively small sample size 2-It was a single-center study (ZagazigUniversity).3Diagnosis of metabolic diseases requires more specific diagnostic tests.

\section{Conclusion}

IEMs are a rare cause of epilepsy but seizures and epilepsy are common in IEM, where the central nervous system carries the principal burden of disease. Many of these disorders are amenable to specific treatments and hence timely and appropriate diagnosis is essential to prevent irreversible brain damage. This requires knowledge about the clinical presentation, standardized vitamin trials, and availability of biochemical tests for diagnosis. IEMs that remain undiagnosed by clinical and biochemical testing, next-generation sequencing with gene panels, and whole exome sequencing may increase the diagnostic yield Compared with the positive rate of the urine metabolic screening tests in high risk infants suggest probability of the presence of a metabolic disease, which will need further specific investigations to determine the possible treatable cases. This is of fundamental importance for directing the awareness of 
general practitioners and pediatricians towards the metabolic disorder.

\section{REFERENCES}

(1) Durmus N, Kaya T, Gültürk S, Demir T, Parlak M, Altun A:The effects of L type calcium channels on the electroencephalogram recordings in WAG/RIJ rat model of absence epilepsy. Eur Rev Med Pharmacol Sci. 2013;17:1149-1154.

(2) Brodie MG: Road to refractory epilepsy: The Glasgow story.Epilepsia 2013; 54:5-8.

(3) Zhen H, Zhen H, Dong Z: Definition of drugresistant epilepsy: Unified proposal forwarded by the project team of International Union of Antiepileptic Treatment Strategy Committee. Chin J Neurol. 2010;43:487-492.

(4) Berg AT, Vickrey BG, Testa FM, Levy SR, Shinnar S, DiMario F, Smith S: How long does it take for epilepsy to become intractable? A prospective investigation. Ann Neurol. 2006;60:73-79. doi: 10.1002/ana.20852.

(5) Vitiello G ,De Clemente V,Della Casa R, Romano A ,Rosa M ,Parenti G:Epilepsy in inherited metabolic disorders: A paediatric series. Minerva Pediatr 2012; 64:513-520.

(6) Xiaomei W, Cunming J, Yingbo Q: Screening diagnosis and treatment progress of inherited metabolic diseases on new born children. Inter J Gen. 2012;35:21-24.

(7) Kaspar H, Dettmer K, Chan Q, Daniels S, Nimkar S, Daviglus ML, Stamler J, Elliott P, Oefner PJ: Urinary amino acid analysis: a comparison of iTRAQ-LC-MS/MS, GC/MS, and amino acid analyzer. J Chromatogr B Analyt Technol Biomed Life Sci. 2009;877:1838-1846. doi: 10.1016/j.jchromb.2009.05.019.

(8) Prasad AN and Hofmann GF: Early onset epilepsy and inherited metabolic disorders :Diagnosis and management. Can J Neurol 2010;43:487-492.

(9) Campos HD: Tandem mass spectrometry as screening for inborn errors of metabolism. Rev Med Chil. 2011;139:1356-1364.(In Spanish)
(10) Prasad AN, Levin S, Rupar CA and Prasad C: Menkes disease and infantile epilepsy. Brain Dev. 2011; 33: 866-87

(11) Shevell MI, Ashwal S and Donley D: Practice Parameter: Evaluation of the child with global developmental delay: Report of the quality standards subcommittee of the American Academy of Neurology and the Practice Committee of the Child Neurology Society. Neurology, 2003; 60:367-80.

(12) Laila MD, Sawsan MD and Fadia MD : Screening for Organic Acid Disorders among Egyptian Children with Clinically Suspected Neurometabolic Disorders, Research Journal of Medicine and Medical Sciences, 2009; 4(2): 369-385.

(13) Stockler S, Schutz PW and Salomons GS: Cerebral creatine deficiency syndromes: clinical aspects, treatment and pathophysiology. Subcell Biochem, 2007;46:149 -166

(14) Gibson K, Halliday JL, Kirby DM: Mitochondrial oxidative phosphorylation disorders presenting in neonates: clinical manifestations and enzymatic and molecular diagnoses. Pediatrics, 2008; 122(5):1003-1008

(15) Mokhtar MM, Kotb SM, Ismail SR : Autosomal recessive disorders among patients attending the genetics clinic in Alexandria. Eastern Mediterranean health journal,1998; 4(3):470-9.

(16) Greenberg $M T$ : Attachment and psychopathology in childhood. In: Cassidy J, Shaver PR, eds. Handbook of Attachment: Theory, Research, and Clinical Applications. New York, NY: Guilford Press Inc,2002;469496.

(17) Saudubray JM, Ogier de Baulny $H$, Charpentier $C$ : Clinical approach to inherited metabolic diseases. In: Fernandes J, Saudubray $\mathrm{JM}$, van den Berghe G, Alter JH, eds. Inborn Metabolic Diseases.4th ed. New York, NY: Springer; 2006:4-41.

How to cite this article: Tawfik FE, Abo-Alfotoh MN, Arafa MA, Khalifa NA. Simple urine metabolic screening in children with refractory epilepsy in Zagazig University childrens. ZUMJ 2019; 25 (1): 39-44. 